\title{
Unpacking the Causal Chain of Financial Literacy
}

\author{
Fenella Carpena, Shawn Cole, Jeremy Shapiro, and Bilal Zia ${ }^{1}$
}

\begin{abstract}
A growing body of literature examines the causal impact of financial literacy on individual, household, and firm level outcomes. This paper unpacks the mechanism of impact by focusing on the first link in the causal chain. Specifically, it studies the experimental impact of financial literacy on three distinct dimensions of financial knowledge. The analysis finds that financial literacy does not immediately enable individuals to discern costs and rewards that require high numeracy skills, but it does significantly improve basic awareness of financial choices and attitudes toward financial decisions. Monetary incentives do not induce better performance, suggesting cognitive constraints rather than lack of attention are a key barrier to improving financial knowledge. These results illuminate the strengths and limitations of financial literacy training, which can inform the design and anticipated effects of such programs.
\end{abstract}

Keywords: Financial Literacy, Financial Knowledge, Causal Mechanism, Impact Evaluation

JEL Codes: C93, D14, G21, O12

\footnotetext{
${ }^{1}$ University of California at Berkeley, Harvard Business School, GiveDirectly, and the World Bank, respectively. We thank Saath Microfinance for their constant support on this research project. We also thank Anamaria Lusardi and Arie Kapteyn for comments, and the World Bank Development Impact blog and the World Bank All About Finance blog for coverage.
} 


\section{Introduction}

Financial literacy has come to play an increasingly important role in financial reform across the world. While modern technology, investments, and liberalization have made new financial products and services widely available, much of the population remains ill equipped to make informed financial choices or to evaluate complex financial products (Lusardi and Mitchell, 2007). In response to the perceived problem of limited financial literacy, governments, firms, and non-profit organizations have devoted vast resources to financial education programs, targeted to reach tens or even millions of individuals in the coming years.

Yet, to date, there is very little rigorous evidence on the impact of financial education. While some rigorous evaluations of financial literacy programs are now underway, the focus seems to be mostly on measuring end outcomes such as behavior change or financial product take-up, and not much on the mechanism of impact - i.e. why and how do financial literacy programs impact financial behavior?

In this paper, we use a randomized experiment to unpack the causal mechanism of financial education. We focus on the intermediary impacts of a five-week comprehensive video-based financial education program in India with modules on savings, credit, insurance and budgeting. We specifically measure the effect on three distinct dimensions of financial knowledge: (1) numeracy skills (e.g. computing interest rates), (2) basic financial awareness (e.g. bank account opening requirements), and (3) attitudes towards financial decisions (e.g. belief in insurance products). To enhance our understanding of the determinants of financial literacy, we complement financial education with a pay-for-performance treatment, where some individuals are provided with greater incentives to pay attention to the training program by receiving monetary rewards for their performance on a follow-up knowledge test. This follow-up test was administered to both the treatment and control groups between two and three weeks after the program intervention. Our large sample, consisting of over 1,200 individuals randomized at the individual level, enables us to detect even relatively small effects of financial literacy training on the various dimensions of financial knowledge. 
Measuring effects on financial knowledge is critical for understanding the potential impacts of financial literacy programs. Although financial literacy training has been promoted heavily around the world, research studies thus far find limited effects on financial behavior (Cole, Sampson, and Zia, 2011). This muted evidence may be due to several reasons. On the one hand, financial literacy programs may not be effective; financial behavior may be difficult to change, and the interventions, which typically involve a "generic" short course adapted to the local environment, may not be relevant, informative, or interesting for the target population.

On the other hand, it is also possible that financial education programs are effective, but measuring impacts on financial behavior is quite challenging. Financial knowledge has typically been measured using standard questions that rely heavily on the numeric and computational ability of respondents, for example asking them to compare two different loan repayment plans, one stated as a percentage APR and the other as a fixed cash payment. It is no surprise that nearly all surveys show a strong correlation between financial literacy score and mathematical ability. But is this really a measure of financial knowledge? Indeed, many financial choices we face in the real world require calculating interest rates and estimating returns, so perhaps financial knowledge and mathematical ability go hand in hand. However, financial literacy programs may also affect financial decision-making through other channels, for instance by making individuals and households more aware of product choices available to them, equipping them to ask the right questions of financial providers, encouraging them to seek professional and personalized financial advice, and changing their attitudes towards purchasing and recommending formal financial products and services. These alternate channels may be as important, if not more, than enhancing numeracy skills. Our study contributes to the literature by carefully examining how financial knowledge is measured, as well as the different layers of knowledge that may be affected by financial education.

Determining effects on financial knowledge is likewise important for establishing the channels between financial literacy training and financial outcomes. Since financial literacy programs are carried out in specific environments, uncovering mechanisms is crucial for generalizing research results to other settings. Nevertheless, the current impact evaluation literature, generally 
speaking, often says little about the economic and social processes leading to any impacts, and is limited in external validity (Deaton, 2010; Ravallion, 2009; Rodrik, 2009). Our study attempts to fill this gap with respect to the impact of financial literacy. By focusing on intermediary improvements in financial knowledge, we provide feedback for the hypothesis that increased financial knowledge is the first step in the causal chain towards changes in financial decisions.

Our results are quite stark. We find that financial education has a very limited role in equipping individuals to evaluate complex financial trade-offs that require high numeracy skills. We do not find that financial education permits individuals to choose the loan option that minimizes expense, to select the most appropriate savings or insurance product, or to create a budget effectively. What is striking is that even individuals who are provided monetary incentives for their performance on the knowledge test are unable to answer such questions correctly. These results indicate that a financial education program that does not specifically address numeracy has little impact on an individual's ability to make financial calculations. Indeed, combining financial literacy education with mathematics training may be necessary to improve financial numeracy.

In contrast, we find that the financial literacy program we study leads to large and statistically significant improvements in individuals' awareness of financial products and services available to them, as well as their familiarity about the details of such products and services. Specifically, individuals who received financial literacy training are 5 percentage points more likely to know the concept of a household budget, 17 percentage points more likely to know minimum bank account opening requirements, and 20 percentage points more likely to understand unproductive loans.

We likewise find that financial education changes respondents' attitudes towards purchasing and recommending formal financial services or financial planning tools. In particular, when hypothetically asked to give financial advice, treated individuals are 5 percentage points more likely to suggest the use of a productive loan, 9 percentage points more likely to suggest buying an insurance product, and 21 percentage points more likely to suggest making a budget to track 
household income and expenditure.

Our results suggest the following sequential channel through which financial literacy training may be effective. Financial literacy education may first increase awareness of and change attitudes towards financial products, then improve numerical ability to compare financial options, and subsequently change financial behavior. The results of this paper provide strong evidence for the first step in this causal framework. We also have follow up surveys currently ongoing in the field to measure differences in financial behavior as well as longer-term numeracy skills. These surveys will allow us to test whether changes in financial awareness and attitudes result in better financial decisions, or whether there are constraints, other than financial knowledge, to changing financial behavior.

Our results also have important implications for how financial literacy is measured and evaluated. The finding that financial literacy programs do not immediately make recipients better financial product evaluators suggest the use of a broader measure of financial literacy, one that does not focus exclusively on questions that require high numeracy skills or calculating financial tradeoffs, but instead includes a healthy combination of basic financial awareness and attitudinal questions. Our paper provides a startling list of such questions to complement existing measures of financial literacy.

Finally, from a practical and policy perspective, our findings provide information for designing more effective financial education programs. Our results suggest that rather than emphasizing financial numeracy skills such as adding expenses or estimating interest rates, familiarizing individuals about the financial products or financial planning tools available to them may be more effective in enhancing financial knowledge. Furthermore, although many financial choices we face in the real world, like comparing the costs of loans for example, do require some form of arithmetic, our findings suggest that increasing an individual's financial sophistication through financial literacy training would be a daunting task; even monetary incentives for performance do not induce better performance, suggesting that cognitive constraints rather than lack of attention are a key barrier to improving financial knowledge. Other complementary approaches, 
such as regulating the supply of credit or strengthening consumer protection measures, may be more appropriate in helping individuals avoid costly financial options.

The rest of this paper proceeds as follows. Section II describes related literature on financial literacy. Section III describes the study design and setting. Section IV provides summary statistics and randomization checks, and Section V presents our results. Section VI concludes. Appendices I and II describe the content of our financial literacy and health videos, and present our financial knowledge survey questions, respectively.

\section{Financial Literacy Mechanism and Measurement}

A growing literature in economics examines the impact of financial literacy programs and related interventions on financial outcomes, but the results so far have been inconclusive. In the developed world, for example, Duflo and Saez (2003) conduct a randomized experiment in which staff members of a US university were offered a small financial incentive to attend an employee benefits fair. The benefits fair was designed to promote awareness about retirement savings accounts, but the authors find only a small increase in retirement plan enrollment. Also in the US, Bertrand and Morse (2010) consider the effects of providing information on the costs of payday borrowing. Their results indicate that an information treatment reinforcing the addingup of interest over time reduces the likelihood that an individual renews a payday loan.

In developing countries, much less is known about the impact of financial literacy programs, although the findings have likewise been mixed. In Indonesia, Cole, Sampson and Zia (2011) study the impact of a financial literacy program tailored to teach unbanked households in Indonesia about savings accounts. While they find no effect on the general population, they find a modest increase in the demand for savings account among those with low initial levels of financial literacy. The impact of financial and business education on entrepreneurial outcomes is a little more promising: Karlan and Valdivia (2010) find that a business education program improves record-keeping, though not profits, among microfinance borrowers in Peru; Bruhn and Zia (2011) find significant impacts of a business training program on business investment and 
production processes among young entrepreneurs in Bosnia and Herzegovina; and Drexler, Fischer, and Schoar (2010) find that a rule-of-thumb training for micro-entrepreneurs in the Dominican Republic increases the likelihood that they keep accounting records and calculate monthly revenues.

This compendium of studies suggests that while financial literacy programs may be effective to some extent, measuring the impact of such programs is quite challenging. By and large, the findings mentioned above are based on behavioral outcomes such as opening a savings account, keeping financial records, investing in a business, or computing business earnings. Yet, if financial literacy is a precursor to financial behavior, then determining improvements in the former is necessary to understand the channels leading to changes in the latter. Furthermore, if improvements in financial literacy are required to change financial behavior, then it would be difficult to detect behavioral outcomes, since these would be situated at the end of the causal chain. Overall, the literature has overlooked a critical component in evaluating financial education programs: the intermediary impact on financial literacy levels following the intervention.

Many financial literacy surveys in high-income countries exhibit two approaches to measuring financial literacy (OECD, 2005). The first measures respondents' understanding of financial terms and their ability to apply financial concepts to particular situations, and the second asks respondents for a self-assessment of their financial understanding and knowledge, as well as their perceptions and attitudes towards financial instruments and decision. The survey questions that have by now become the standard measure of financial literacy, however, are those developed by Lusardi and Mitchell (2009) on numeracy, inflation, and diversification. ${ }^{2}$ These questions have been included in various surveys to evaluate financial literacy in many corners of the world, including the US, the Netherlands, Italy, Germany, and New Zealand. They have likewise been

\footnotetext{
${ }^{2}$ The financial literacy questions developed by Lusardi and Mitchell (2009) are the following: (1) Suppose you had $\$ 100$ in a savings account and the interest rate was 2 percent per year. After 5 years, how much do you think you would have in the account if you left the money to grow: more than $\$ 102$, exactly $\$ 102$, or less than $\$ 102$ ?, (2) Imagine that the interest rate on your savings account was 1 percent per year and inflation was 2 percent per year. After 1 year, would you be able to buy more than, exactly the same as, or less than today with the money in this account?, (3) Do you think that the following statement is true or false? "Buying a single company stock usually provides a safer return than a stock mutual fund."
} 
adapted to measure financial literacy in research conducted in developing countries, such as Indonesia (Cole, Sampson, and Zia, 2011), India (Cole, et. al., 2010), Sri Lanka (de Mel, McKenzie, and Woodruff, 2009), and Mexico (Hastings and Tejada-Ashton, 2008).

While Lusardi and Mitchell (2009) provide a standard set of questions to assess financial literacy, these measures are not necessarily comprehensive and may not be appropriate in many settings. Indeed, Lusardi and Mitchell (2009) write that it is "imperative to expand the range of measures of financial literacy, so as to better evaluate the types of problems that people find most difficult." The developing context in particular has specific characteristics, including high poverty, low access to finance, and lack of consumer finance protection, that are essential for measuring financial literacy (Holzmann, 2010). For instance, in an environment where most households are uneducated and hold informal savings, it may be important to assess financial literacy based on knowledge of bank account opening requirements, as opposed to ability to calculate interest rates. Thus, the concept of financial literacy should be extended, especially in the developing country context.

Our paper contributes to the literature in the following ways. First, we examine the intermediary impacts of financial literacy education, a question that has not received much attention in the literature thus far. In so doing, we provide evidence for the first step in the causal framework through which financial literacy affects financial outcomes. From a policy perspective, a better understanding of this causal sequence can also help direct scarce resources towards enhancing specific features of financial literacy programs. Second, we test a broader measure of financial

literacy that includes three dimensions: numeracy skills, basic financial awareness, and attitudes towards financial decisions. Numeracy skills are those that involve calculating interest rates, adding income, and similar computations; basic financial awareness consists of knowledge about the details of a budget, savings account, and loan processing fees; attitudes towards financial decisions involve individual perspectives about the benefits of financial products. The following section describes in more detail the measure of financial literacy that we implement, as well as our study design and setting.

\section{Study Design}


The population for this study comprises 1,200 urban households in Ahmadabad, a metropolitan city in the state of Gujarat, India. Approximately half of our sample respondents are clients of the microfinance program of Saath, our partner non-government organization; the other half are associated with Saath's other urban development programs (e.g. livelihood), but are not microfinance clients.

To manage the large sample size, we conduct the study in four waves, and the sample sizes per wave are reported in Table 1A. We study two treatments, all randomly assigned at the individual level, designed to improve financial literacy and affect financial behavior.

First, we study a video-based financial education program. To avoid bias from Hawthorne-type effects, the control group in each wave is assigned to watch health education videos. Second, we provide financial incentives to participants based on their performance on a financial or health literacy test administered two to three weeks after the conclusion of training. All participants in both treatment and control groups are requested to complete this follow-up test. Table 1B presents the experimental design for our study, and Appendix I describes the content of our videos. A description of the interventions follows below.

\section{A. Financial Literacy Treatment}

In each wave, two-thirds of all participants are randomly invited to attend a video-based financial literacy training program; the remaining one-third are invited to video-based training on health issues. ${ }^{3}$ All training sessions are held once a week for five consecutive weeks, and each session lasts for two to three hours. We chose to provide health training (instead of no training at all) to the control group to ensure that both treatment and control experienced the same level of "disruption" in their everyday activities. The financial literacy training videos cover the

${ }^{3}$ Once participants are recruited and assigned individual identification numbers, we stratify participants by neighborhood, whether the participant is a client of Saath MFI, and gender. Within each strata, a Stata program assigns a random uniform number to each participant. The random uniform number is then sorted, and based on this sort order, integer sequences of 1 through 3 are generated. Respondents with integer value of 1 and 3 are assigned to treatment, and those with value of 2 are assigned to control. 
following five topics: budgeting, savings, loans, insurance, and a final summary video. The health training videos cover topics unrelated to financial literacy: cleanliness and hygiene; midwife, maternal and child health; condoms, AIDS and syphilis; and night-blindness. See Appendix I for more details on the content of these modules. Respondents receive Rs. 50 (USD 1) show-up fee for each session they attend, and are provided with transportation to and from their home to the training center.

\section{B. Pay for Performance Treatment}

Our 5-week video training concludes with a short follow-up survey administered two to three weeks after the final training session. The follow-up survey consists of both financial literacy and health questions, drawn from topics discussed in the video trainings. All participants are informed in advance that they would be offered the chance to earn additional compensation based on their performance on these follow-up questions. We vary which questions individuals are paid for. Half the participants (again selected at random, individually) are paid for correct answers to questions related to the videos they watched (financial literacy or health), and the other half are paid for correct answers to topics that are not covered in their video training (general knowledge or reverse questions - financial literacy training participants get paid for health questions and vice versa). Participants knew from the beginning whether health, financial literacy, or general knowledge questions would determine their compensation.

\section{Summary Statistics}

\section{A. Summary Statistics}

Baseline summary statistics for our sample are provided in Table 2. Households in our sample comprise on average six members, with an average household monthly income of Rs. 5250 (USD 115). A little more than half (57 percent) of our respondents are female, and a vast majority is married. Respondents in our sample on average have limited schooling: 47 percent completed elementary school, but only 4 percent completed secondary school. 
In addition to standard data on household demographics and respondent characteristics, our baseline survey measures financial knowledge, attitudes, and preferences. We measure discount rates in the standard manner, by asking respondents to provide the minimum amount they would be willing to hypothetically accept in one month in lieu of a hypothetical payment of Rs. 350 today. Respondents in our sample report relatively high monthly discount rates; the median is 0.14 and the average is 1.58 . We also measure risk aversion by allowing respondents to choose between a certain payment of Rs. 10, or playing a lottery which pays out Rs. 25 or Rs 0 with probability of 1/2 each. 17 percent of our sample chose the safe bet, and these respondents are coded as risk averse.

Additionally, we measure numeracy skills through a series of eight mathematics questions. The mean score for these mathematics questions is 4.7 out of 8 . Almost all respondents could answer a simple addition question ("How much is $4+3$ ?"), but only about 50 percent was able to answer a multiplication question correctly ("What is 3 multiplied by 6?"). Even fewer respondents were able to make percentage calculations correctly ("What is 8 percent of 100?"), with close to half responding "do not know" to this question. Cole, Sampson, and Zia (2011) find similar numeracy levels among households in Indonesia.

Finally, we measure baseline levels of financial literacy based on the following three questions: (1) "If you borrowed Rs. 5,500 and were charged 12 percent interest per month, how much interest would you pay in the first month?”; (2) "Suppose you had Rs. 100 in a savings account and the same amount saved at home, which of the two will yield returns at the end of the year?”; and (3) "Suppose your friend inherits Rs. 10,000 today and his brother inherits Rs. 10,000 three years from now. Who is richer because of the inheritance?” Measured financial literacy is low in our sample, with an average score if 1.6. Similar to the mathematics questions, few respondents (less than 10 percent) were able to calculate interest rates correctly in question 1, and over 60 percent responded "do not know" to this question. In contrast, almost all respondents were aware that a savings account yields positive returns (question 2), but only 58 percent of our sample was able to correctly identify the time value of money (question 3), lower than what Lusardi and Mitchell (2009) find among respondents in the US. 
Attrition in our sample is fairly low, at 7 percent of the entire sample over the four waves.

\section{B. Randomization Checks}

Table 3 provides a test of the randomization. The p-values in column 3 of Table 4 report the statistical significance of a test for the difference between the mean of those invited to financial literacy video training (treatment) and those invited to health video training (control). The means of baseline characteristics appear to be similar across treatment and control groups.

\section{Experimental Results}

We examine the types of financial knowledge that are affected by financial education and pay for performance treatments. Since treatments are randomized, we estimate causal effects with the following equation,

$$
Y_{i}=\alpha+\sum_{j=1}^{3} \beta_{j} \text { Treatment }_{j i}+\sum_{k} \text { StrataDummy }_{k}+\varepsilon_{i}
$$

where $Y_{i}$ represents an outcome measure of financial knowledge for individual $i . j=1$ to 3 represent three of the four possible combinations of financial literacy and pay for performance treatments; the omitted category is the pure control group, which received only health training. To accommodate the large sample size, our study was conducted in four waves. In each wave, treatments are stratified based on gender, whether the respondent is currently a client of Saath MFI, and neighborhood. Thus, we include strata dummies in equation (1) for precision. We also note that since neighborhoods are mutually exclusive across waves, we do not add wave fixed effects. Furthermore, in each study wave, participants are assigned to attend a particular

classroom session which meets at the same time every week for the duration of the training program. Classroom sessions consist of either all financial literacy training participants, or all health training participants. In estimating equation (1), we cluster standard errors at the classroom session level. 
Our outcome measures $Y$ are dummies for correct answers to financial literacy questions in the follow-up survey. The survey questions cover 3 different dimensions of financial knowledge: (1) numeracy skills, (2) basic financial awareness, and (3) attitudes towards financial decisions. Since our study was conducted over four waves, we were able to refine our measure of financial knowledge as the study was underway. In particular, in Wave 1, we began with financial knowledge questions based on numeracy skills, and we included such questions in the follow-up survey from Wave 1 onwards. From Wave 2 onwards, we added questions on basic financial awareness, and beginning in Wave 3, we added questions on attitudes towards financial decisions. In the discussion that follows, we investigate the effects of the financial literacy training and pay for performance treatments on these three dimensions of financial knowledge. Appendix II provides the exact wording of the financial knowledge questions we implement.

\section{A. Financial Numeracy Skills}

We first focus on outcomes relating to financial numeracy skills. Table 4 presents OLS regressions from estimating equation (1), where the sample consists of respondents in all four phases. The outcomes of interest are dummies for correct answers to financial literacy questions

that rely on numeracy. Specifically, these questions require respondents to compare insurance costs, calculate interest rates, or compute income and expenses. These questions were developed after an initial pilot, and were designed to be closely related to topics covered in the financial literacy training videos.

Nevertheless, the point estimates on the treatment variables in Table 4 suggest that the financial literacy program has no effect on respondents’ abilities in numerically comparing financial tradeoffs. Moreover, individuals who were provided with greater financial incentives to pay attention to the financial literacy training program do not perform any better on these questions.

\section{B. Basic Financial Awareness}

Next, we consider treatment effects on a second dimension of financial knowledge, namely, basic financial awareness. In addition to financial numeracy questions, we measure respondents’ knowledge of fundamental financial planning concepts, as well as details of financial products, 
in the follow-up survey beginning in Wave 2. For example, respondents are asked about their understanding of deposit insurance, health insurance cover, or the purpose of a household budget. Results for such financial literacy questions are presented in Tables 5 and 6 .

We find that the financial literacy training has a large, positive impact on basic financial awareness. Column (1) of Table 5 shows that relative to health training participants respondents who receive financial literacy training are 4.5 percentage points more likely to know that both income and expenses are included in a household budget. In column (2), we examine the effects of both financial literacy and pay for performance treatments and find that participants who received both treatments are 5.5 percentage points more likely to know that both income and expenses are included in a household budget, compared to participant who received neither financial literacy nor pay for performance on financial literacy questions. The F-test of adding up all three coefficients has a p-value of 0.078 , however the marginal impact of pay for performance is not significant.

The remaining columns in Table 5 and Table 6 continue to show this positive treatment effect for most basic awareness questions. Notably, financial literacy training participants are 17 percentage points more likely to know the minimum amount necessary to open a bank account, and 20 percentage points more likely to understand that borrowing for consumption is an unproductive loan. These effects are quite large and represent a 20-30 percent increase over the control group means, since less than two-thirds of the pure control group was able to answer such questions correctly.

Finally, columns 7 and 8 of Table 6 use as the dependent variable a composite measure of all basic financial literacy questions. The results show that aggregate basic financial awareness increases by 7.7 percentage points due to financial literacy training; the combined effect of training and pay for performance is also statistically significant, though pay for performance does not provide any additional, statistically significant improvements. 


\section{Financial Attitudes and Perceptions}

The third dimension of financial knowledge that we consider is attitudes towards financial decisions. From Wave 3 onwards, we included questions in the follow-up survey wherein respondents are presented with hypothetical situations, and are asked about the financial products or financial advice they would suggest in the given scenario. Tables 7 and 8 present results for these attitudinal questions.

Note that the difference between Tables 7 and 8 is how we code our response measures. Some of the attitudinal questions (presented in Appendix II) do not have a singular correct answer, but rather have an ascending range of correct answers. For example, the first question in this series asks respondents to suggest an action to a friend who works in an injury-prone environment. The options available to the respondent are "quit job," "purchase health/life/accident insurance,” or “increase savings.” The most financially savvy advice is to purchase an insurance product, however increasing savings can also contribute to a financial buffer in case of injury. Table 7 considers only the best answer as being correct and creates a dummy variable as the dependent variable. In Table 8, we create a continuous variable with a range from 0 to 1 , coded with greater weight placed on the insurance option, and an intermediary non-zero weight on the savings option.

The results from both methods are similar. We find that those who received financial literacy training are significantly more likely to offer good financial advice for insurance, budgeting, and productive loans. Moreover, the aggregate financial attitudes and perception score is significantly higher for those who received financial literacy training.

As with the other dimensions of financial knowledge, we do not find any additional benefit of the pay for performance treatment. One explanation is that the participants did not find our offer credible and hence did not apply additional effort focusing on the videos. This is unlikely, however, since we do find significant pay for performance effects for individuals who were assigned to health videos and were paid for answers to health related questions. 
The more likely explanation, and one that we intend to explore further in our follow-up surveys, is that financial literacy and knowledge is simply harder to teach and individual cognitive constraints are a significant barrier to improving financial knowledge. Health training may be easier to understand for a couple of important reasons: (a) it does not involve numeric computation; and (b) it is likely more salient in peoples' lives, for example participants themselves may have experienced preventable sickness in the past or know someone who gave birth with an untrained midwife.

\section{Conclusion}

In this paper, we report experimental results of a study to measure the impact of financial education on three layers of financial knowledge - numeracy skills, basic financial awareness, and attitudes towards financial decisions - among low-income urban households in India. Our findings suggest that financial education has limited effects in increasing financial numeracy. Specifically, we do not find that financial literacy training fosters individual abilities to calculate and compare interest returns, insurance costs, or household income and expenses. Even when provided with monetary incentives, respondents are unable to answer these questions correctly. We find, however, that financial education influences participants' awareness of and attitudes towards financial products and financial planning tools available to them.

Our results have important implications for advancing both research and policy. While many financial choices we face in the real world require calculating interest rates or estimating returns, our findings indicate that measuring financial literacy should not exclusively focus on questions that require high numeracy skills. Financial education programs may affect financial decision making through channels other than financial numeracy, for instance by making individuals and households more aware about the details of financial products, or changing their attitudes towards purchasing and recommending formal financial products and services. These alternate channels may be as important, if not more, than enhancing numeracy skills. 
Furthermore, our finding that financial education influences financial awareness and attitudes provides evidence for establishing the causal framework between financial literacy training and financial outcomes. These changes in awareness and attitudes may allow individuals who have received the training to access appropriate financial products in the future. Our ongoing follow up data collection will allow us to assess whether this is true. 


\section{References}

Angrist, J. and V. Lavy (2009). The effect of high-Stakes high school achievement awards: Evidence from a school-centered randomized trial. American Economic Review 99 (4), 13841414.

Agarwal, S., G. Amromin, I. Ben-David, S. Chomsisengphet, and D. Evanoff (2009). Do financial counseling mandates improve mortgage choice and performance? Evidence from a legislative experiment. Fisher College of Business Working Paper No. 2008-03-019.

Ashraf, N., D. Karlan, and W. Yin (2006). Tying Odysseus to the mast: Evidence from a Commitment Savings Product in the Philippines. Quarterly Journal of Economics 121 (2), 635672.

Banerjee, A., E. Duflo, R. Glennerster, and C. Kinnan (2010). The miracle of microfinance? Evidence from a randomized evaluation. Working paper.

Bernheim B. D., M. Garrett, and D. M. Maki (2001). Education and saving: The long-term effects of high school financial curriculum mandates. Journal of Public Economics, 80 (3), 435465.

Christelis, D., T. Jappelli, and M. Padula (2006). Cognitive abilities and portfolio choice. CEPR Discussion Paper No. 5735.

Cole, S., and N. Fernando (2008). Assessing the importance of financial literacy. Asian Development Bank: Finance for the poor.

Cole, S., T. Sampson, and B. Zia (2010). Prices or knowledge? What drives deman for financial services in emerging markets? The Journal of Finance, forthcoming. 
Cole, S., and G. Shastry (2010). Is high school the right time to teach self-control? The effect of financial education and mathematics courses on savings behavior. Working paper.

Karlan, D., and M. Valdivia (2010). Teaching entrepreneurship: Impact of business training on microfinance clients and institutions. Review of Economics and Statistics, forthcoming.

Lusardi, A., and O. Mitchell (2007). Financial literacy and retirement preparedness: Evidence and implications for financial education. Business Economics 42, 35-44.

Lusardi, A., and O. Mitchell (2009). How ordinary consumers make complex economic decisions: Financial literacy and retirement readiness. NBER Working Paper No. 15350.

Mulainathan, S., and E. Shafir (2009). Savings Policy \& Decision-Making in Low-Income Households. In Michael Barr and Rebecca Blank (Eds.), Insufficient Funds: Savings, Assets, Credit and Banking Among Low-Income Households. Russell Sage Foundation Press.

Stango, V. and J. Zinman (2009). Exponential growth bias and household finance. The Journal of Finance 64 (6), 2807-2849. 


\section{Appendix I: Content of Financial and Health Literacy Videos}

This appendix describes the content of our video-based interventions:

\section{Financial Literacy videos}

\section{Session 1: Budgeting}

Budgeting is the building block of household financial planning and management and the video aims at making the audience appreciate the need of keeping a household budge today in order to plan and save for a better tomorrow. The video trains participants in making a household budget and tries to dissociate the utility of keeping a budget with the nature of the income; it being a common belief among people that only those with regular and surplus income can keep a household budget. Instead the video brings out how budgeting can be especially useful for those with small incomes to bring down unnecessary expenditure and meet unforeseen expenses.

\section{Session 2: Savings}

Building on the previous session, the savings session begins by introducing the audience to the plight of Ramiben, a vegetable vendor who is caught in a debt trap given her spendthrift habits and inability to appreciate the need of accumulating small savings. Apart from educating the audience on the need of savings, the session dwells on the merit of saving in a bank vis a vis home and is a comprehensive guide on the various savings instruments present in the market.

\section{Session 3: Loans}

The session addresses three primary questions, namely: what to take a loan for (productive versus unproductive reasons), where to take a loan from (bank and MFI versus moneylenders) and how to cost a loan (comparing interest rate versus comparing interest rates, accounting for hidden costs like documentation fee and other terms of the loan that are likely to impact its cost).

\section{Session 4: Insurance}

The session begins by introducing the audience to various kinds of risks one faces in life and how insurance can act as a "shield," protecting us against life's uncertainties. The video further talks about the various types of insurance available in the market and the companies one can 
approach to purchase insurance. Insurance is a complex product and choosing a policy that is best suited to one's needs can be baffling given the dizzying array of options available in the market. The video therefore attempts to explain the design an insurance product; it cost components and factors that can affect the latter.

\section{Session 5: A Concluding Video}

"If my neighbor or friend can do it, so can I"--this is the essence of the last video which seeks to instill confidence in the audience s' ability to put in practice the lessons in financial management and planning taught in the last month. Interviewing people from the slums who practice budgeting and savings, who exercise discretion at the time of taking out a loan and who hold an insurance policy, the video aims to highlights how these people have been able to improve their lives with better financial management despite small and erratic incomes.

\section{Health Education videos}

\section{Session 1: Cleanliness \& Hygiene}

It talks about the essentials of cleanliness and hygiene like washing hands with soap, drinking portable filtered water; using toilets for defecation. We put these forth as basic but extremely crucial aspects of personal health and hygiene that can help keep households disease-free.

\section{Session 2 \& 3: Dai (midwife) \& Maternal and Child Health}

Session two and three discuss various issues relating to maternal heath and child care, both during pregnancy and after childbirth. It highlights the importance of monitoring pregnancy through regular ante-natal check-ups (ANC) and using the services of a trained midwife or a doctor for delivering the baby. Breastfeeding and immunization are described as crucial aspects of child health. Besides, since diarrhea is a common problem faced by infants, the sessions educate them on how to deal with it and what are the immediate remedies.

Session 4: Condoms, AIDS \& Syphilis 
This session focuses mainly on sexually transmitted diseases like AIDS \& Syphilis. It gives detailed information on how these diseases can be contracted and what precautions need to be taken in order to protect ones family. The video also touches upon various myths related to sexually transmitted diseases and attempts to sensitize audience to the need of seeking informed advice on the subject. Reference is also made on how newborns can be saved from these diseases, in spite of their mothers suffering from the same. Towards the end, use of condoms as a means to prevent these diseases is stressed upon.

\section{Session 5: Night Blindness}

Night Blindness is common amongst children and pregnant women. The session cautions the audience against the various myths about the disease and suggests how simple measures like a regular diet rich in Vitamin A and iron can cure the ailment. 


\section{Appendix II: Financial Knowledge Survey Questions}

\section{Financial Numeracy Skills}

1. Assume you purchased a health insurance policy on the $1^{\text {st }}$ of January and you suffer an insurable loss of Rs. 1000 on $31^{\text {st }}$ December due to an accident. Would you be better off if you had purchased an insurance policy with
A. Rs. 3,000 cover and Rs. 950 premium
B. Rs. 2,000 cover and Rs. 900 premium

2. If you had the choice, would you prefer to
a. Receive Rs. 70 in cash 10 months from now
b. Save Rs. 50 at 5 percent interest per month for 10 months

3. Suppose you had Rs. 50 to save. You could either save this for 1 month in an account which earns 14 percent interest per month, or save it for 1 month in an account that earns 2 percent interest per week. Which would you choose, 14 percent per month or 2 percent per week?

4. Assume you have purchased a medical insurance policy and suffer an accident which results in Rs. 3500 of hospital fees. Would you be better off if you had purchased an insurance policy with
A. Rs. 3,000 cover and Rs. 950 premium
B. Rs. 2,800 cover and Rs. 800 premium

5. We would like to tell you a short story about the income and expenditures of a tailor. We would then like you to use this sheet (give worksheet) to determine if in a month, this tailor is saving money or if his monthly expenditures exceed his monthly income.

Jerembhai is a tailor in Vasna. Each week he makes Rs. 1500 from his work. He also sells the scraps from his work, for this he earns Rs. 200 each week. Each month Jerembhai must pay Rs. 1000 for the rent of his shop. He also spends Rs. 200 per week on his food and household goods. In addition to this he spends about Rs. 50 per week on tea and snacks. He must pay Rs. 500 each month for the education expenses of his children. Some time age, Jerembhai took a loan to 
purchase his sewing machine. He pays an installment of Rs. 250 each week for this loan. He also pays Rs. 150 per month for a life insurance policy.

\section{$\underline{\text { Basic Financial Awareness }}$}

1. Shantiben is preparing a budget for her household. Which of the following needs to be included in the budget?
A. Income only
B. Expenses only
C. Both

2. Do you think you can open a savings account in a bank with amount as low as Rs 50 or 100 ?

3. Sukhiben's expenses are more than her income. Her friend Najmabanu tells her that writing a budget can help bring down her unnecessary expenses. Do you agree with Najmabanu or not?

4. Suppose I have a savings account in a bank and the bank closes down for some reason, will I get my money back?

5. Nileshbhai recently bought accident insurance with Rs 10,000 cover. The next day, he met with an accident and had to be hospitalized. He incurred Rs. 5,000 in hospital fees. How much do you think the medical insurance policy will pay for?

6. Iqbalbhai is 20 years old and Ashokbhai is 30 years old. If they were to buy life insurance of Rs 1 lakh for 20 years, who between the two to your mind will have to pay higher premium?

7. Manojbhai recently borrowed some money from a local moneylender. He wanted to buy some clothes for his children for Diwali (festival). What do you think about Manojbhai's loan? 


\section{Financial Attitudes and Perceptions}

1. Rameshbhai does plastering on tall buildings. It is a dangerous job and he is worried that if he gets injured his family's income will become inadequate to meet their needs. If Rameshbhai comes to you for advice what would you suggest?
A. Quit job
B. Purchase health/life/ accident insurance
C. Increase savings

2. Vimlaben has a very bright child who is currently in secondary school, but will probably do well in university. She is worried how her family will pay for the child's education. If Vimlaben comes to you for advice what would you suggest?
A. Buy child life insurance policy
B. Borrow money from a moneylender
C. Open a savings account in a Bank
D. Save at home
E. Discontinue education
F. Other

3. Kashiben has two sons. Her husband and two sons are earning members of the household and contribute towards household income. However Kashiben does not know what is the household's total income and expenditure. How do you think Kashiben can track her income and expenditure?
A. Open a savings account
B. Start making a household budget
C. Buy life insurance for her husband and sons

4. Nareshbhai currently drives a rented auto rickshaw. He wants to purchase his own auto rickshaw but does not have the money and is considering taking out a loan for the same. If 
Nareshbhai comes to you for advice what will you suggest - should he take out a loan or should he not?

5. Sajidbhai recently got married. He and his wife are considering buying a TV. They do not have enough savings and will need to take out a loan. Sajidbhai has two options: (1) He can take a loan from the moneylender and a relative and get a bigger amount in loan to buy a big TV, or (2) He can take a loan only from a relative and buy a smaller TV. What would you advise Sajidbhai and his wife? 
Table 1: Sample Size and Experimental Design

This table describes our sample and experimental design. Panel A describes the number of respondents in each of the four waves of the study. Panel B describes the experimental design. Study participants were first randomized into financial literacy training or health training. Additionally, all respondents in the sample were randomized into pay for performance treatment.

Panel A. Sample size for each phase

\begin{tabular}{llll}
\hline Wave & Sample size & \\
1 & 279 & & \\
2 & 421 & & \\
3 & 243 & & \\
4 & 405 & & \\
Total & 1348 & & \\
\multicolumn{5}{l}{ Panel B. Experimental design } \\
\hline Financial lit- & Pay for per- & N & \\
eracy videos & formance & & 33.09 \\
\hline Yes & Yes & 446 & \\
Yes & No & 452 & 16.93 \\
No & Yes & 229 & 16.39 \\
No & No & 221 & \\
\hline
\end{tabular}


Table 2: Summary Statistics

This table provides summary statistics for our sample. The sample consists of respondents in Ahmedabad, India.

\begin{tabular}{lrrr}
\hline & Median & Mean & SD \\
\hline Household characteristics & & & \\
Household size & 6.00 & 5.89 & 2.49 \\
Household monthly income (Rs.) & 4300.00 & 5250.31 & 5297.48 \\
Household has phone & 0.84 & \\
Household has non-farm enterprise & 0.26 & \\
Household has water connection & 0.78 & \\
& & & \\
Respondent characteristics & & 0.57 & \\
Female & 39.00 & 38.58 & 8.93 \\
Age & & 0.98 & \\
Married & & 0.81 & \\
Hindu & & 0.47 & \\
Completed elementary school & & 0.04 & \\
Completed secondary school & & \\
Saath MFI client & 5.00 & 4.70 & 2.03 \\
& 2.00 & 1.60 & 0.62 \\
Math score (out of 8) & & & \\
Financial literacy score (out of 3) & & 0.94 & \\
& & 0.86 & \\
Has hard time saving (self-report) & & \\
Interested in financial matters (self-report) & & & \\
Discount rate (monthly) & 0.14 & 0.49 & \\
Inconsistent time preferences & & 0.17 & \\
Risk averse & & & \\
\hline
\end{tabular}

Discount rate has been trimmed $2 \%$ from the top 
Table 3: Randomization Test

The p-values in column 3 report the statistical significance of a test for the difference between the mean of those invited to financial literacy video training (treatment) and those invited to health video training (control).

\begin{tabular}{lrrr}
\hline & Treatment & Control & p-value \\
\hline Log per capita income (monthly) & 5.290 & 5.258 & 0.856 \\
Female & 0.572 & 0.571 & 0.965 \\
Age & 38.401 & 38.944 & 0.292 \\
Household has non-farm enterprise & 0.255 & 0.269 & 0.584 \\
Married & 0.978 & 0.980 & 0.787 \\
Hindu & 0.815 & 0.811 & 0.858 \\
Completed elementary school & 0.478 & 0.467 & 0.702 \\
Completed secondary school & 0.036 & 0.036 & 0.994 \\
Math score (out of 8) & 4.688 & 4.736 & 0.686 \\
Saath MFI client & 0.490 & 0.484 & 0.848 \\
Financial literacy score (out of 3) & 1.607 & 1.573 & 0.348 \\
Interested in financial matters (self-report) & 0.857 & 0.869 & 0.567 \\
Has hard time saving (self-report) & 0.947 & 0.940 & 0.621 \\
Inconsistent time preferences & 0.493 & 0.489 & 0.878 \\
\hline
\end{tabular}




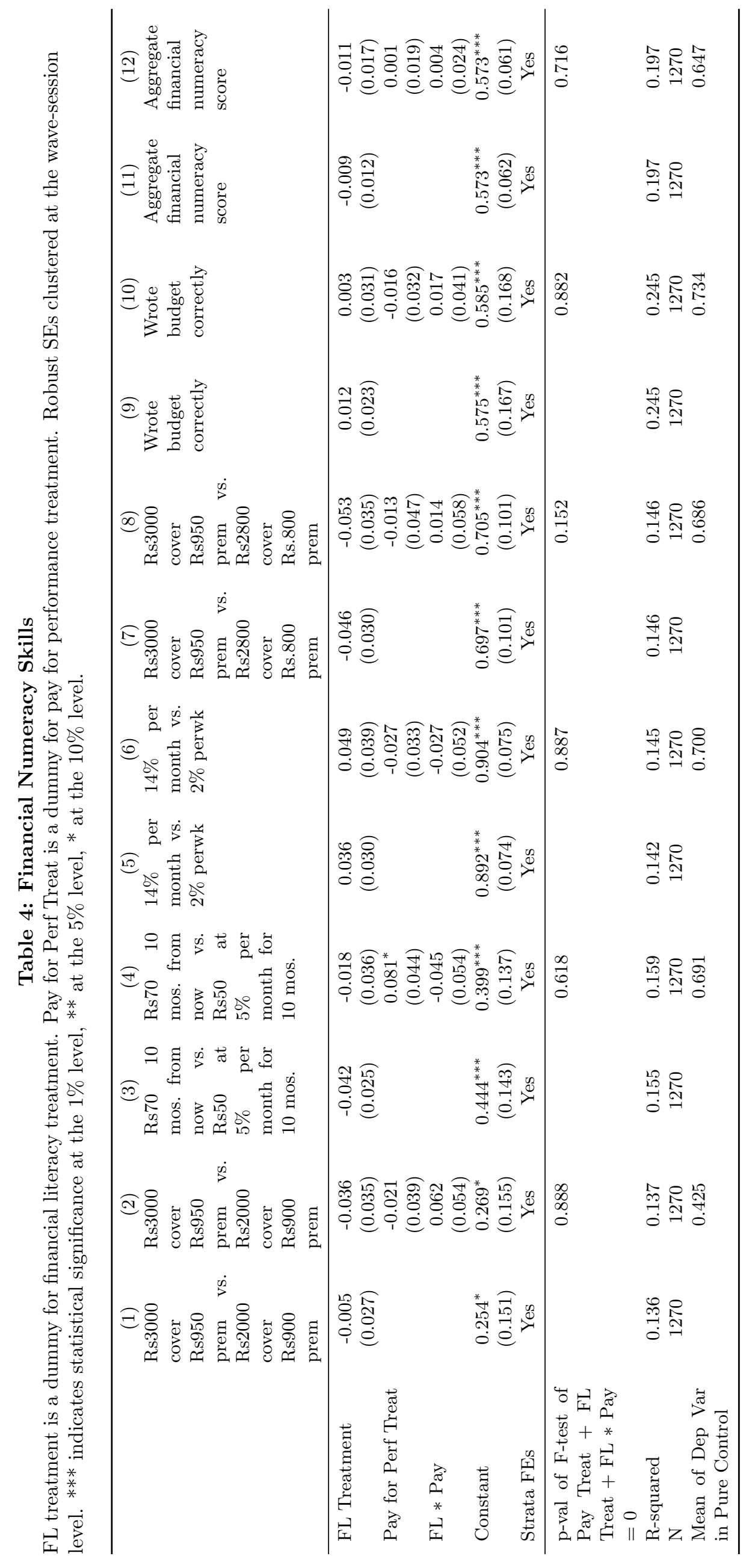




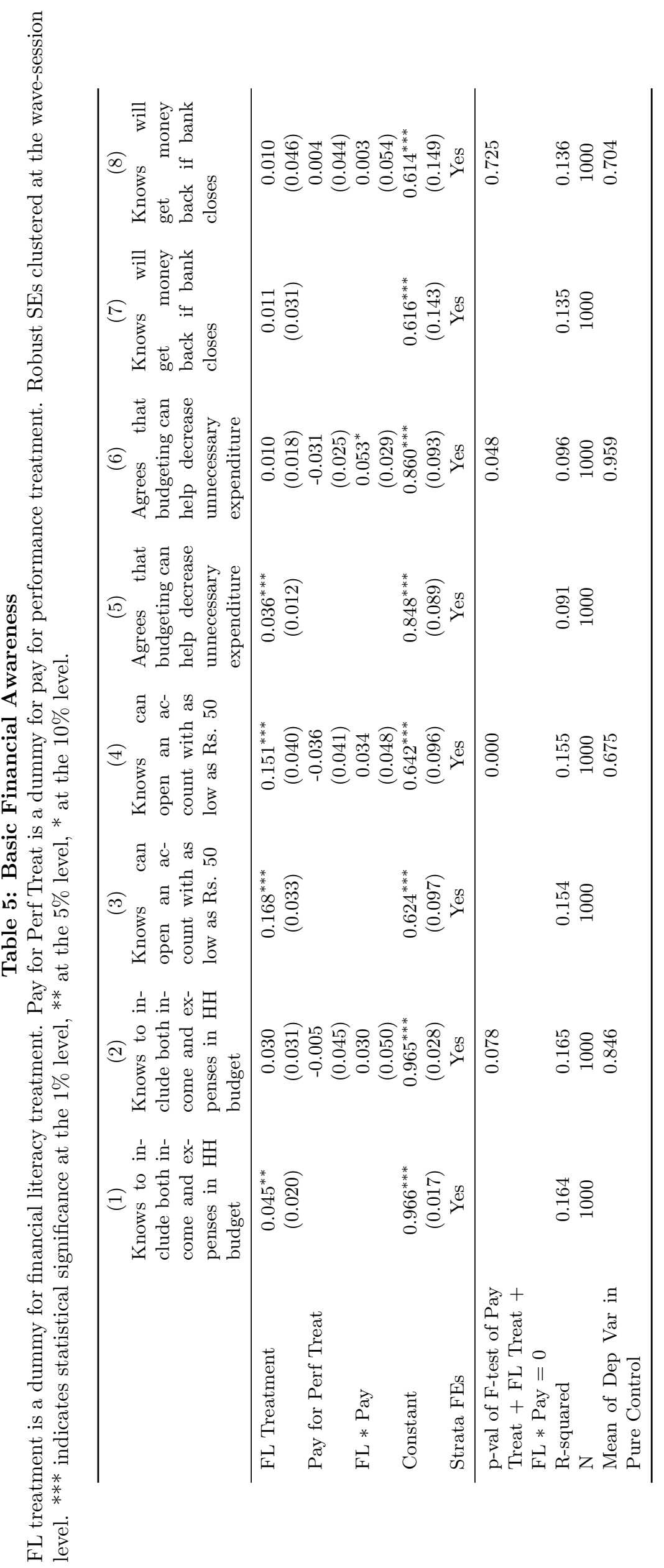




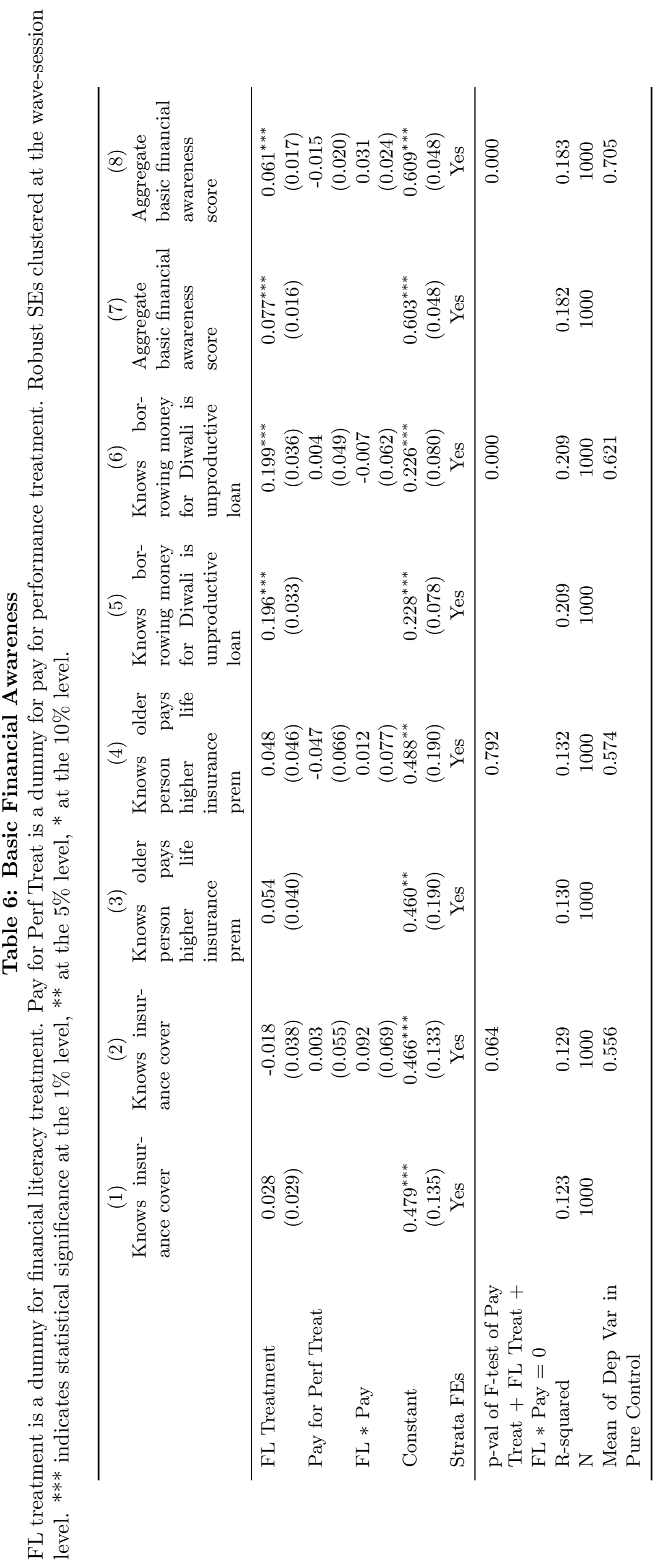




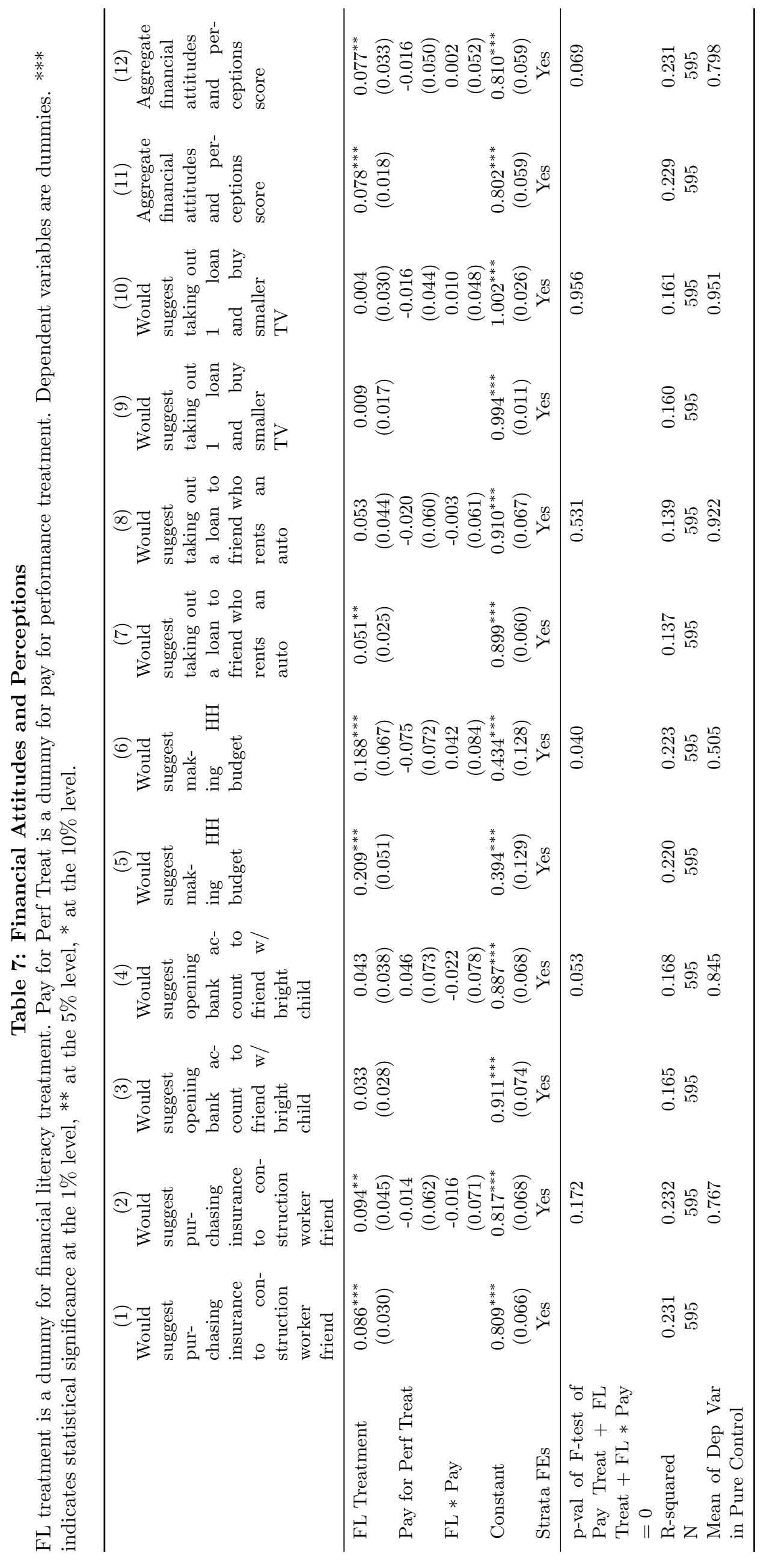


范

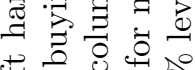

의의

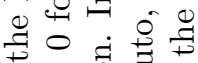

$g$ +r.

ఫ

주요

ब

50 금

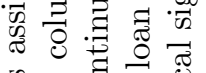

幽

कै

.7 50 bo

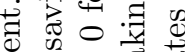

bo of I व

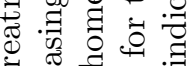

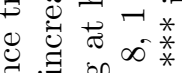

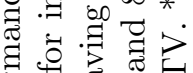

亮

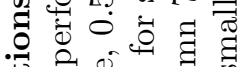

훙의

०

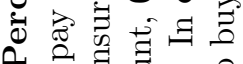

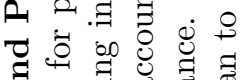

ซ है

of 형

寻

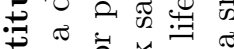

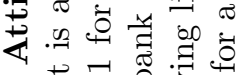

त छ

计

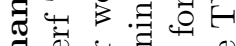

$\exists$ 河

至

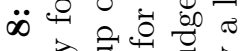

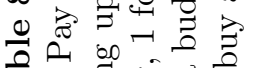

2

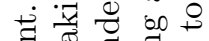

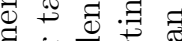

등

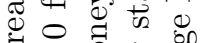

人

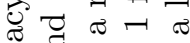

ซี ซี

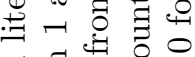

.

긍

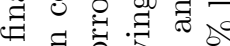

可

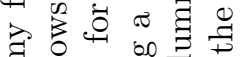

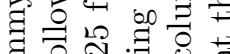

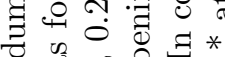

क वे के के

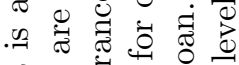

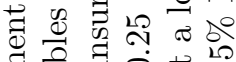

$\exists .70$

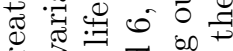

$\forall \bar{v}$

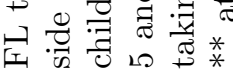

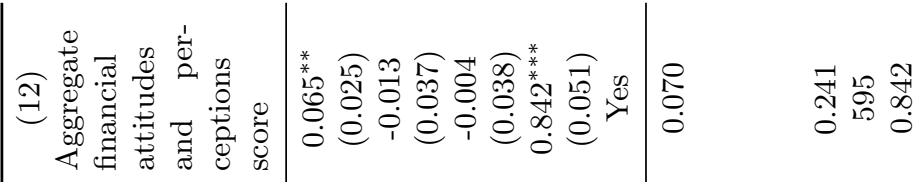

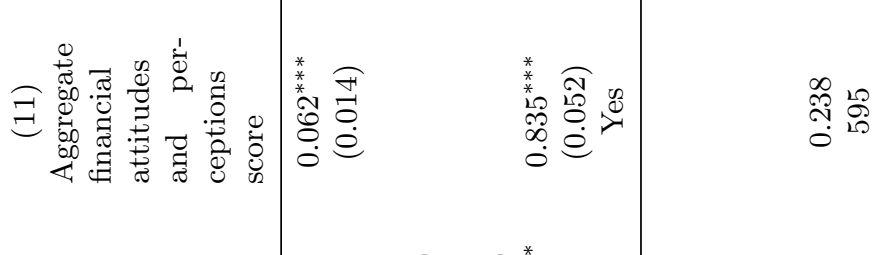

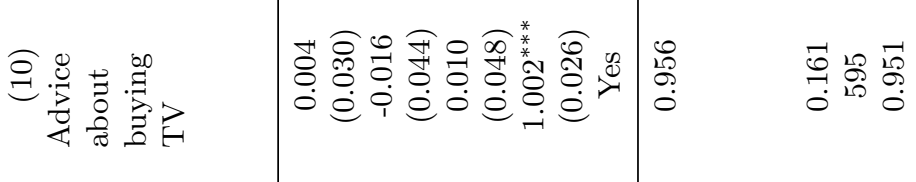

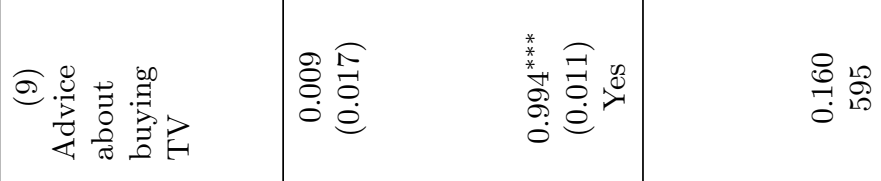

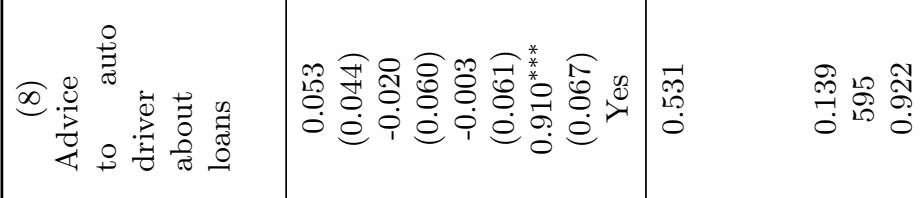

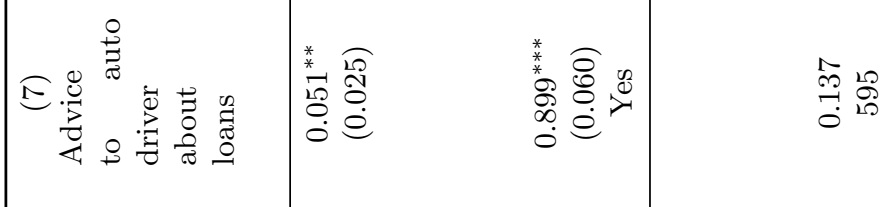

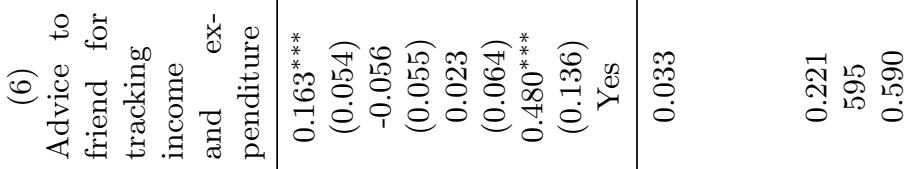

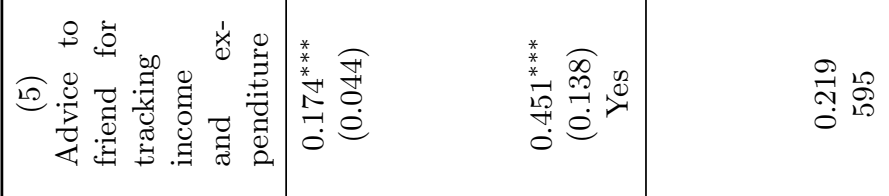

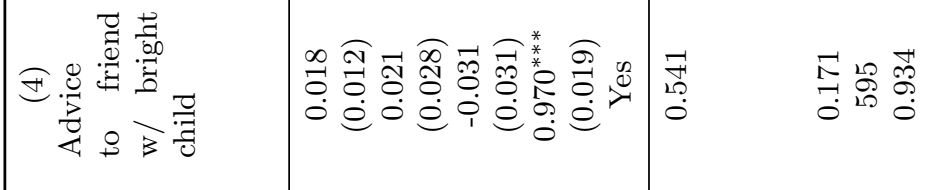

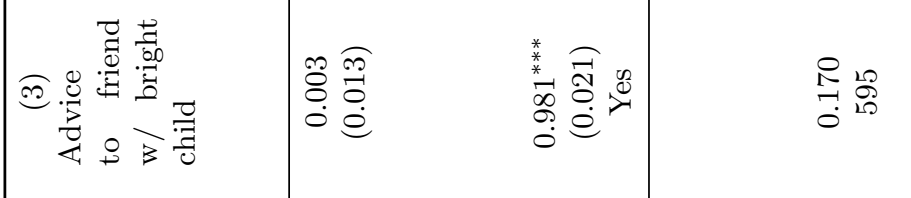

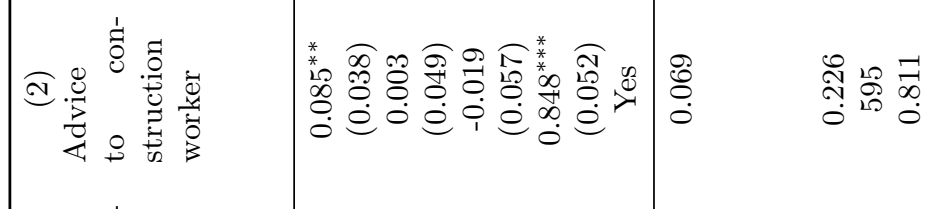

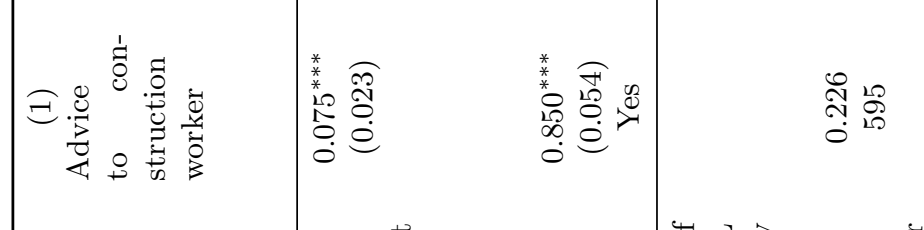

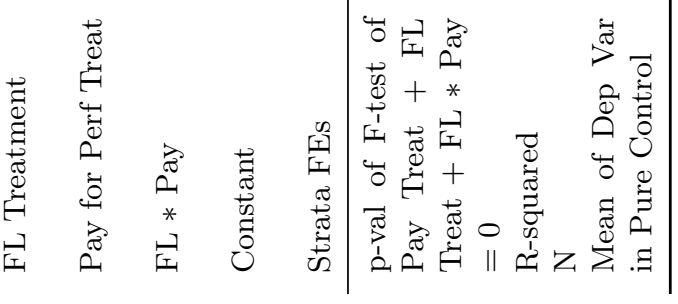

